\title{
Perancangan Blanking Compound Dies pada Mesin Press Sinao Kapasitas 250 kN untuk Proses Pembuatan Ring M20
}

\author{
Erwanto*, Taufiq Hidayat, Nidia Lestari, Joko Waluyo \\ Jurusan Teknik Mesin, Fakultas Teknologi Industri, Institut Sains \& Teknologi AKPRIND \\ Yogyakarta, Jl. Kalisahak No. 28 Yogyakarta \\ *Penulis korespondensi: erwanto201664@gmail.com
}

Histori artikel: diserahkan 22 September 2021, direviu 25 September 2021, direvisi 29 September 2021

\begin{abstract}
In this design, the product we want to make is a die for the $M 20$ ring because the die we designed is helpful for student learning (practicum) at the Mechanical Technology Laboratory. The ring manufacturing process is carried out using one blanking compound dies. The blanking and piercing processes are carried out in one operation, thus saving time and money. This dies planning includes the process of designing dimensions and other supporting tools using the SolidWorks 2017 application. This design aims to produce blanking compound dies designs on press machines for the M20 ring manufacturing process with little or no defects and estimate the cost of making blanking compound dies. The method of analysis using Solidworks 2017 software includes displacement, von misses stress, safety factor. The results obtained from the 2017 SolidWorks analysis are to estimate the wear life of the punch and die to anticipate product failures. The material used in this ring is SAPH44O as defined in JIS 3113, starting from $2 \mathrm{~mm}$ to $14 \mathrm{~mm}$. At the same time, the one we use for the M20 ring has a thickness of $2 \mathrm{~mm}$. Based on the dies design calculations and data analysis that has been carried out, it is concluded that the use of blanking compound dies can reduce product defects due to dimensional accuracy in the dies and accelerate the production process of ring making.
\end{abstract}

Keywords: Ring M 20, Blanking Compound Dies and Blanking and Piercin

DOI : https://doi.org/10.18196/jqt.v3i1.12615

WEB : https://journal.umy.ac.id/index.php/qt/article/view/12615

\section{PENDAHULUAN}

Dunia industri terutama dalam bidang manufaktur, mengalami perkembangan yang signifikan. Tuntutan yang harus dipenuhi bukan hanya kualitas barang yang tinggi, tapi juga waktu pengerjaan yang singkat dan tepat, untuk itu diperlukan sebuah mesin yang mampu memenuhi semua tuntutan-tuntutan dalam industri manufaktur Mesin-mesin di industri manufaktur salah satunya adalah mesin pres. Pengepresan merupakan sebuah proses mencetak metal dengan menggunakan alat bantu berupa dies dan mesin pres. Dies merupakan salah satu alat yang digunakan dalam membuat komponen dengan bahan dasar pelat. Dies membutuhkan alat pendukung berupa punch dan die. Diperlukan suatu dies yang simpel dan efisien, untuk menghasilkan produk yang baik secara kualitas dan kuantitasnya. Pada perancangan kali ini produk yang dibuat adalah dies untuk pembuatan produk ring M20 karena perancangan dies berguna untuk pembelajaran praktikum mahasiswa di Laboratorium Teknologi Mekanik Institut Sains \& Teknologi AKPRIND.

Ring berfungsi sebagai penguat ikatan antara mur dan baut. Jika baut mengikat komponen lain tanpa mur, maka ring berguna sebagai pengunci baut dengan part itu. Jika memasang baut tanpa ring, baut bias terlepas atau malah mengunci terlalu kuat dengan mur atau komponen lain. Fungsi dari ring selain memperkokoh ikatan baut, juga agar baut atau mur tidak merusak komponen yang diikatnya. Material yang digunakan untuk ring pada perancangan ini adalah pelat SAPH 440. Pelat 
SAPH didefinisikan sebagai baja lembaran canai panas untuk aplikasi struktural automotive. Baja lembaran canai panas merupakan lembaran baja, pelat dan gulungan rendah karbon yang dihasilkan canai panas. Baja canai panas sering juga disebut pelat hitam. Baja SAPH dalam standar industi jepang dikodekan dengan JIS G 3113:2006 dan dibagi menjadi 4 yaitu SAPH 310, SAPH 370, SAPH 400, SAPH 440 yang masing-masing memiliki komposisi kimia dan mechanical properties yang berbeda-beda. Komposisi kimia penyusun pada SAPH 440 ditunjukkan pada Tabel 1.

TABEL 1. Komposisi kimia SAPH 440 (Zhao et. al., 2019)

\begin{tabular}{ccccccc}
\hline $\mathrm{C}$ & $\mathrm{Si}$ & $\mathrm{Mn}$ & $\mathrm{P}$ & $\mathrm{S}$ & $\mathrm{Al}$ & $\mathrm{N}$ \\
\hline $0,1 \sim 0,2$ & 0,01 & $1,0 \sim 1,5$ & 0,013 & 0,002 & 0,035 & 0,002 \\
\hline
\end{tabular}

Lavrinenko et al. (2019), melakukan pengembangan dies stamping untuk pembuatan komponen berbentuk ring dengan metode kompresi. Berdasarkan hasil studi teoritis dan eksperimental yang dilakukan sebelumnya dari proses stamping berbentuk ring menggunakan metode kompresi, desain dies satu tahap dikembangkan, dalam penggunaannya memungkinkan pembuatan ring dalam berbagai ukuran. Rumus untuk menentukan dimensi benda kerja utama diperhalus dan diberikan contoh perhitungan proses pada benda kerja dengan metode kompresi. Simulasi komputer dari proses kompresi benda kerja dalam paket perangkat lunak PAM-STAMP menunjukkan bahwa koefisien offset permukaan netral akan berbeda saat menganalisis benda kerja menggunakan metode kompresi dan regangan benda kerja. Hasilnya, kemungkinan untuk mendapatkan. Rumus yang dihasilkan untuk menentukan ukuran benda kerja oval primer dapat digunakan untuk menghitung proses stamping pada bagian ring dengan menggunakan metode kompresi pada dies stamping yang dirancang.

Tujuan perancangan yang ingin dicapai dalam pembuatan blanking compound dies yaitu menghasilkan rancangan blanking compound dies pada mesin press untuk proses pembuatan ring M20 dengan sedikit kerusakan atau bahkan tanpa cacat. Perancangan yang kita lakukan kali ini memiliki inovasi dan berbeda dengan dies untuk ring pada umumnya, hal ini dikarenakan Proses blanking dan piercing dilakukan dalam satu proses, sehingga dapat mengefisienkan waktu dan biaya.

\section{METODOLOGI}

\section{Perancangan Produk}

Tahapan perancangan blanking compound dies untuk proses pembuatan ring M20 ditunjukkan oleh diagram alir pada Gambar 1.

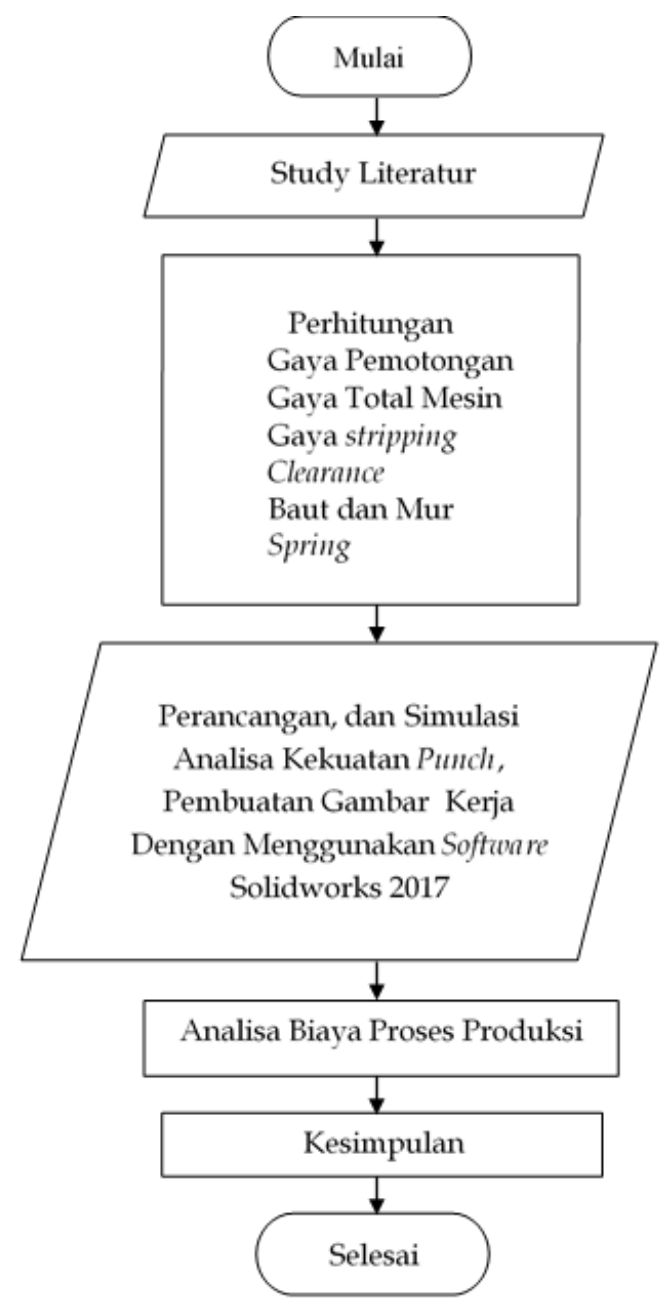

GAMBAR 1. Diagram alir perancangan

\section{Analisis Produk}

Software Solidworks digunakan untuk menganalisa usia keausan. Bagian yang dianalisa meliputi punch atas bawah dan blok pemegang punch. Faktor-faktor yang dianalisa menggunakan software SolidWorks yaitu displacement, von misses stress dan safety 
factor. Material yang digunakan untuk pembuatan produk ring pada perancangan ini adalah pelat baja SAPH 440. Dimensi ring yang akan dihasilkan ditunjukkan oleh Gambar 2. Hariyanto et al. (2020), menganalisis kekuatan rangka mesin pengolah lanting menggunakan Software Autodesk Inventor sebelum mesin tersebut dibuat. Berdasarkan hasil analisis perancangan menggunakan software tersebut mampu mengetahui kekuatan defleksi pada rangka yang menunjukkan bahwa mesin dalam kondisi aman (safety) pada saat dioperasikan (Yudha \& Nugroho, 2020). Analisis simulasi pembebanan menggunakan software merupakan langkah yang tepat sebelum dilakukan pembuatan produk Compound Dies.

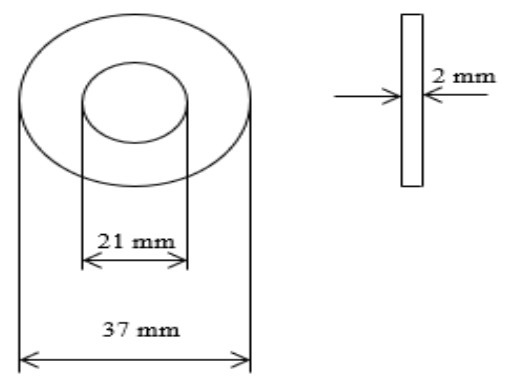

GAMBAR 2. Produk ring M20

\section{Perhitungan pada Proses Perancangan}

1) Gaya pemotongan,

$$
\mathrm{F} \quad=0,7 \times \mathrm{t} \times l(\mathrm{UTS})
$$

keterangan:

$$
\begin{array}{ll}
\mathrm{F} & =\text { Gaya pemotongan }(\mathrm{N}) \\
\mathrm{t} & =\text { Tebal material }(\mathrm{mm}) \\
l & =\text { Panjang tepi potong }(\mathrm{mm}) \\
\mathrm{UTS} & =\text { Tegangan tarik material }\left(\mathrm{N} / \mathrm{mm}^{2}\right)
\end{array}
$$

Dengan menggunakan rumus diatas dan ukuran geometri produk maka gaya pemotongan yang terjadi dapat dihitung.

\section{2) Kapasitas Mesin}

Gaya stripping merupakan gaya yang digunakan untuk menahan material agar tidak terangkat atau terbawa naik pada waktu punch diangkat naik. Besarnya gaya stripper tersebut berkisar antara 2,5\%-20\% gaya total punch. Dalam perancangan ini diambil $10 \%$ dengan pertimbangan benda kerja tidak terlalu berat dan terlalu ringan. Perhitungan stripping pressure $\left(\mathrm{P}_{\mathrm{s}}\right)$ menurut Wilson dan Harvey (1965) dapat dihitung dengan rumus berikut:

$$
\mathrm{P}_{\mathrm{s}} \quad=10 \% \mathrm{LT}
$$

keterangan:

$$
\begin{array}{ll}
\mathrm{L} & =\text { Gaya total punch }(\mathrm{N}) \\
\mathrm{t} & =\text { tebal material }(\mathrm{mm})
\end{array}
$$

\section{3) Perhitungan pegas}

Perancangan dies menggunakan pegas ulir tekan yang akan menerima beban maksimum $25 \mathrm{~kg}$, dengan lendutan 8-10, panjang bebas 30 $\mathrm{mm}$ dan panjang awal $25 \mathrm{~mm}$. Diameter ratarata adalah $18 \mathrm{~mm}$, bahan yang dipakai adalah pegas SUP 4 dengan modulus geser 8000 $\mathrm{kg} / \mathrm{mm}$.

$\tau=K \frac{8 D W_{1}}{\pi d^{3}}=K \frac{8}{\pi} \cdot\left(\frac{D}{d}\right) \cdot \frac{W_{1}}{d^{2}}$

keterangan:

$$
\begin{array}{ll}
\tau & =\text { Tegangan geser }\left(\mathrm{kg} / \mathrm{mm}^{2}\right) \\
\mathrm{K} & =\text { Faktor tegangan Wohl } \\
\mathrm{D} & =\text { Diameter rata-rata }(\mathrm{mm}) \\
\mathrm{W}_{1} & =\text { Beban maksimum }(\mathrm{kg}) \\
\mathrm{d} & =\text { Diameter kawat }(\mathrm{mm})
\end{array}
$$

\section{HASIL DAN PEMBAHASAN}

Perhitungan dan tahapan yang dilakukan untuk perancangan sebagai berikut:

\section{Gaya Pemotongan}

Gaya pemotongan piercing

$$
\begin{aligned}
\mathrm{F} & =0,7 \times \mathrm{x} \times l \text { (UTS) } \\
& =0,7 \times 2 \times 21(440) \\
& =12936 \mathrm{~N}
\end{aligned}
$$

Gaya Pemotongan Blanking

$$
\begin{aligned}
\mathrm{F} & =0,7 \times \mathrm{t} \times l(\mathrm{UTS}) \\
& =0,7 \times 2 \times 37(440) \\
& =22792 \mathrm{~N}
\end{aligned}
$$

Kapasitas dan Gaya Total Mesin

$$
\begin{aligned}
\mathrm{P}_{\mathrm{S}} & =10 \% \times 35728 \times 2 \\
& =7145,6 \mathrm{~N}
\end{aligned}
$$

Diperoleh dari jumlah gaya seluruh proses dan gaya stripping $12936+22792+7145,6$ $=42873,6 \mathrm{~N} \approx 42,8 \mathrm{kN}$ 


\section{Hasil Analisis Software SolidWorks}

Hasil dari part-part yang sudah dianalisa ditunjukan sebagai berikut:

\section{1) Displacement}

Gambar 3 menunjukkan bahwa total deformasi terbesar ada pada pusat punch bawah sebesar $2,769 \mathrm{e}-003 \mathrm{~mm}$, hal ini terjadi karena pusat punch bersinggungan langsung dengan material benda kerja dan punch atas, sedangkan total deformasi terkecil ada pada bagian yang bawah punch bawah yaitu sebesar $1.000 \mathrm{e}-030 \mathrm{~mm}$ karena tidak bersinggunagn langsung.

Hasil simulasi pemegang punch bawah pada Gambar 4 menunjukkan bahwa total deformation terbesar ada pada lubang pusat pemegang punch bawah sebesar $1.044 \mathrm{e}-007$ $\mathrm{mm}$, hal ini terjadi karena bagian tersebut tempat keluar masuknya punch dan total deformasi terkecil ada pada bagian bawah pemegang punch yaitu sebesar $1.000 \mathrm{e}-030 \mathrm{~mm}$ karena bagian tersebut jauh dari lubang keluar masuknya punch.

Hasil simulasi punch atas pada Gambar 5 menunjukkan bahwa total deformasi terbesar ada pada ujung atas punch sebesar 1.900e-002 $\mathrm{mm}$, hal itu terjadi sama seperti punch bawah bagian tersebut bersinggungan langsung denagn material benda kerja dan punch bawah, dan total deformasi terkecil ada pada bagian bawah punch yaitu sebesar $0 \mathrm{~mm}$ hal ini karena jauh dari bagian yang bersinggungan langsung. Deformation blanking akan meningkat dengan meningkatnya kekuatan blanking dan dengan menurunnya kekerasan blanking holder dan sudut geser punch (Yagita et al., 2020)

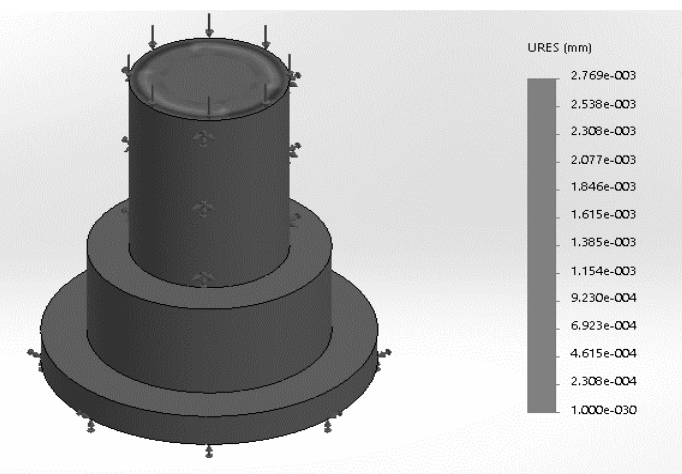

GAMBAR 3. Displacement pada punch bawah

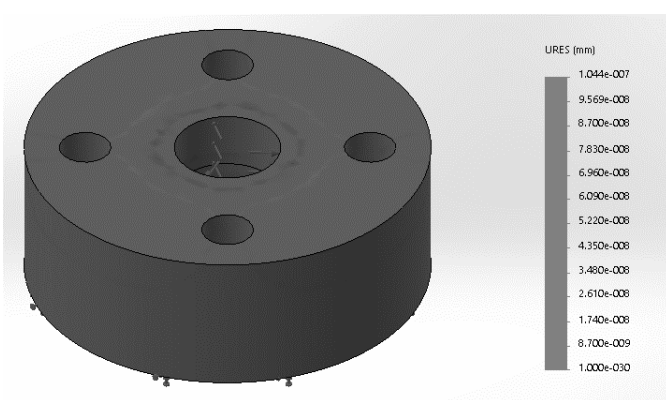

GAMBAR 4. Displacement pada pemegang punch bawah

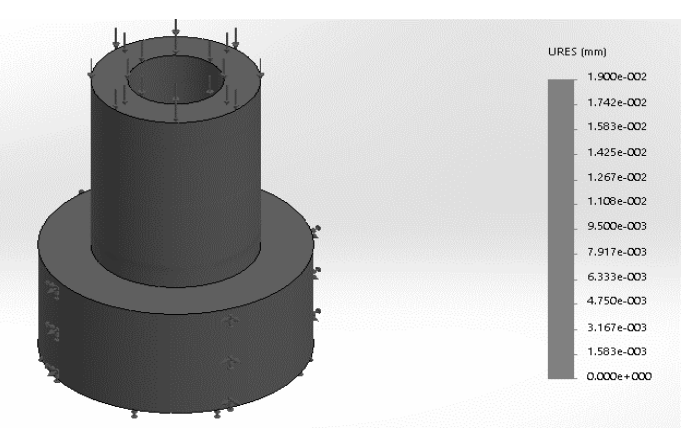

GAMBAR 5. Displacement pada punch atas

\section{2) Von Misses Stress}

Hasil analisis equivalent stress pada komponen blanking compound dies: diartikan stress yang terjadi pada simulasi ini semakin sempit permukaan luasaan permukaan namun gaya tetap maka tegangan semakin besar. Dari simulasi pada Gambar 6 bagian paling merah adalah penopang yang menerima tekanan paling besar dengan nilai maksimal sebesar $6913 \mathrm{e}+007\left(\mathrm{~N} / \mathrm{m}^{2}\right)$, dikarenakan area tersebut berfungsi sebagai pisau pemotong benda kerja sedangkan pada bagian biru ditentukan dengan nilai minimal yaitu sebesar $5217 \mathrm{e}+003\left(\mathrm{~N} / \mathrm{m}^{2}\right)$, area tersebut bukan sebagai pisau sehingga memiliki nilai minimal karena tidak bersinggungan langsung dengan benda kerja.

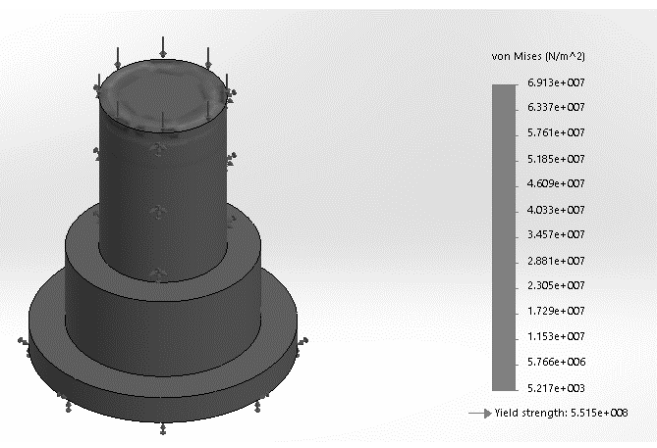

GAMBAR 6. Equivalent stress pada punch bawah 
Gambar 7 menunjukkan bagian paling merah adalah penopang yang menerima tekanan paling besar dengen nilai maksimal sebesar $8275 \mathrm{e}+002\left(\mathrm{~N} / \mathrm{m}^{2}\right)$, karena area tersebut lubang keluar masuknya punch atas sedangkan pada bagian biru ditentukan dengan nilai minimal yaitu sebesar $3120 \mathrm{e}+000\left(\mathrm{~N} / \mathrm{m}^{2}\right)$, karena area tersebut jauh dari pusat lubang.

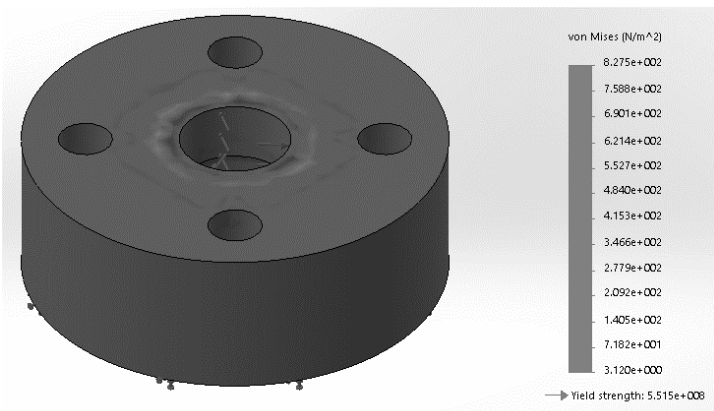

GAMBAR 7. Equivalent stress pada pemegang punch bawah

Gambar 8 bagian paling merah adalah penopang yang menerima tekanan paling besar dengen nilai maksimal sebesar $4837 \mathrm{e}+007$ $\left(\mathrm{N} / \mathrm{m}^{2}\right)$, hal itu karena memiliki perbedaan diameter sehingga area tersebut memiliki nilai maksimal pada bagian biru ditentukan dengan nilai minimal yaitu sebesar 3082e+006 (N/m²), hal itu karena bagian tersebut menyatu dengan pemegang punch atas.

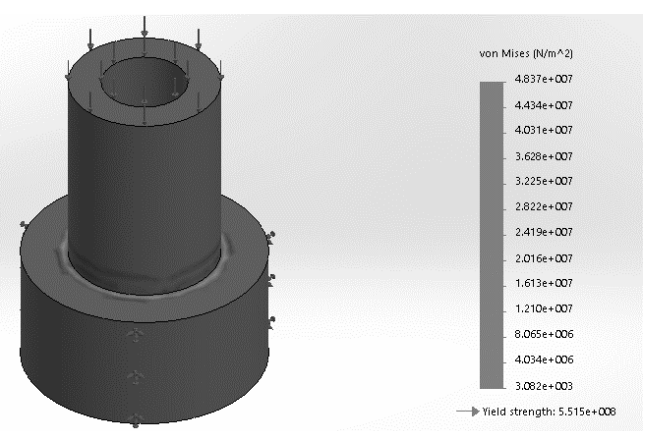

GAMBAR 8. Equivalent stress pada punch atas

\section{3) Safety Factor}

Safety factor atau angka keamanan merupakan salah satu parameter penting untuk menentukan apakah suatu konstruksi itu aman atau tidak. Safety factor merupakan perbandingan antara tegangan ijin bahan dengan tegangan yang terjadi (Sularso \& Suga, 2004). Berikut adalah analisa safety factor pada komponen yang ada pada blanking compound dies.

Analisa safety factor yang terjadi pada punch bawah bisa dilihat pada Gambar 9 Dimana didapatkan hasil FOS maksimal terjadi pada pinggiran punch bawah sebesar 8.000e+001 hal ini terjadi karena bagian tersebut paling beresiko sebab bagian tersebut berfungsi sebagai pemotong benda kerja dan hasil FOS minimal terjadi pada bagian berwarna biru sebesar $1.000 \mathrm{e}+001$, karena area tersebut memiliki risiko paling minim dan area tersebut terhubung dengan pemegang punch bawah.

Analisa safety factor yang terjadi pada pemegang punch bawah bisa dilihat pada Gambar 10. Dimana didapatkan hasil FOS maksimal terjadi pada lubang pusat pemegang punch bawah sebesar $4.500 \mathrm{e}+006$, hal ini dikarenakan bagian tersebut adalah lubang keluar masuknya punch atas dan hasil FOS minimal terjadi pada bagian pinggiran pemegang punch bawah sebesar 2279e+004, karena area tersebut tidak bersinggungan langsung dengan punch atas.

Analisa safety factor yang terjadi pada punch atas bisa dilihat pada Gambar 10 hingga 12 . didapatkan hasil FOS maksimal terjadi pada tengah punch atas sebesar 7.000e+001, hal ini terjadi karena memiliki perbedaan dimensi dan hasil FOS minimal terjadi pada bagin bawah punch sebesar 5.000e+000, hal ini dikarenakan area tersebut terhubung dengan pemegang punch atas.

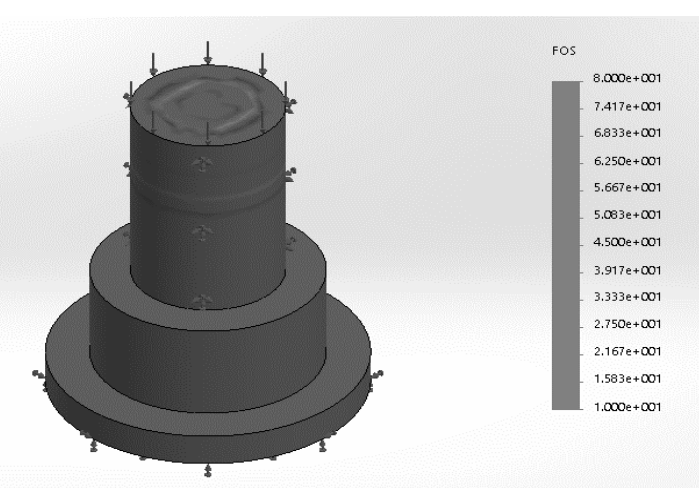

GAMBAR 9. Tampilan safety factor pada punch bawah 


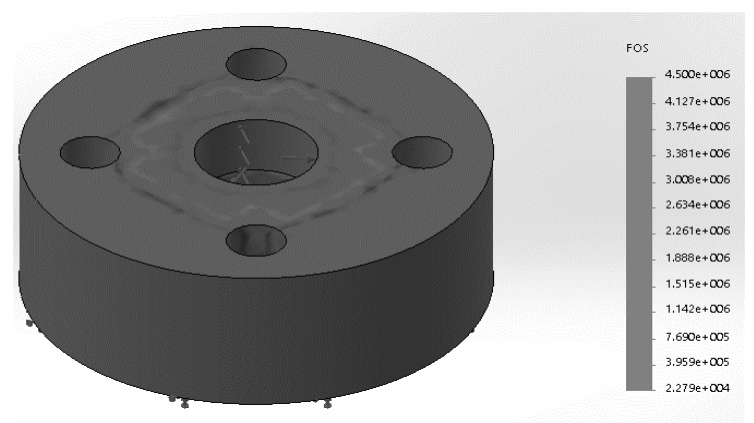

GAMBAR 10. Tampilan safety factor pada pemegang punch bawah
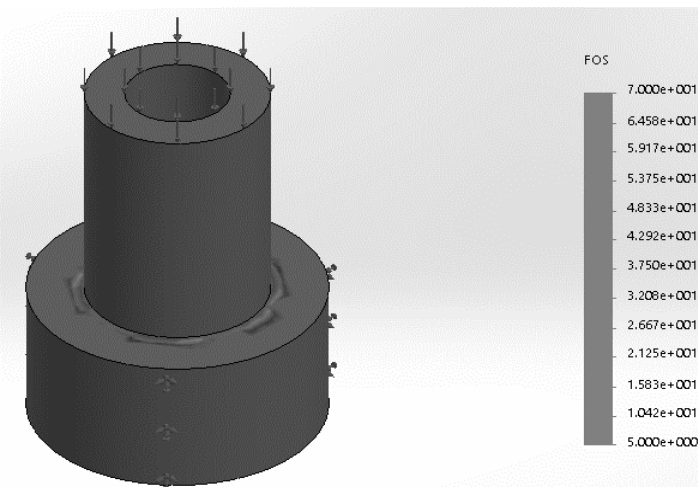

GAMBAR 11. Tampilan safety factor pada punch atas

\section{KESIMPULAN}

Perancangan blanking compound dies ini dapat menghasilkan efisiensi material dalam penggunaannya, karena blanking compound dies diciptakan memiliki ukuran dan akurasi bentuk yang sesuai, sehingga ring M 20 memiliki ukuran yang diinginkan. Hal ini tentu saja dapat menekan biaya produksi pengadaan bahan baku karena material yang terbuang dapat diminimalkan. Penggunaan blanking compound dies dapat menekan adanya cacat produk hal ini dikarenakan kepresisian pada blanking compound dies, serta dapat mendukung pencapaian produksi produk tanpa cacat dalam produksi besar.

\section{DAFTAR PUSTAKA}

Hariyanto, S. D., Papasi, R. G., Munthohani, G. R., Lanekri, I. T., Sastika, I. P., No, J. K., \& Klitren, G. (2020). Perancangan dan Fabrikasi Mesin Pengolah Ubi Kayu untuk Produksi Makanan Ringan Lanting Kapasitas 40 kg/jam. Quantum
Teknika: Jurnal Teknik Mesin Terapan, 2(1), 38-46.

Lavrinenko, V. Y., Polyakov, A. O., \& Mirvelyan, T. A. 2019. Development of the stamp design for ring-shaped parts manufacturing by compression method. Materials Today: Proceedings, 19, 2106-2108.

Sularso \& Suga, K. 2004. Dasar perencanaan dan pemilihan elemen mesin. Jakarta: Pradya Paramita.

Wilson, F. W., \& Harvey, P. D. (Eds.). 1965. Plastics Tooling and Manufacturing Handbook: A Reference Book on the Use of Plastics as Engineering Materials for Tool and Workpiece Fabrication. Prentice-Hall.

Yagita, R., Abe, Y., Munesada, Y., \& Mori, K. I. (2020). Deformation behaviour in shearing of ultra-high strength steel sheets under insufficient blankholding force. Procedia Manufacturing, 50, 2631.

Yudha, V., \& Nugroho, N. 2020. Rancang Bangun Mesin Perajang Singkong dengan Pendorong Pegas. Quantum Teknika: Jurnal Teknik Mesin Terapan, 2(1), 20-26.

Zhao, L. H., Cai, H. C., Weng, S., \& Zheng, S. L. 2019. Effect of pre-strain on the fatigue behavior of SAPH440 steel. Materials Express, 9(9), 10011008. 